\title{
HUBUNGAN TINGKAT PENGETAHUAN DENGAN KUNJUNGAN PASIEN DIARE DI KLINIK SANITASI PUSKESMAS III DENPASAR SELATAN
}

\author{
Ni Made Zeny Pramuli ${ }^{1}$, I Wayan Sudiadnyana ${ }^{2}$
}

\begin{abstract}
Community Health Service played an important role in improving community health status. In 2017, Puskesmas III Denpasar Selatan has low success rate of sanitation clinic program which is 7,04\%. This research is done in order to identify the relationship knowledge level and visits of diarrhea patients at Sanitation Clinic of Puskesmas III Denpasar Selatan. The data is based on the Report of Diarrhea Cases and Sanitation Clinic Visits in 2019 with a cross sectional study through observational analytics. The samples obtained were 54 patients. Statistical analysis using chi square. The average knowledge level categorized as low namely 28 patients (51,9\%), only 24,1\% know the purpose of the sanitation clinic. Most of the diarrhea patients choose not to visit sanitation clinic namely 44 patients (81,5\%). The knowledge level and visits were significantly associated with moderate relationship $(p=0,000$ and $C C=0,44)$. Therefore, the implementation team of sanitation clinic and POA (Plan of Action) are needed, also empowering the community leaders, cadres, families and organizations.
\end{abstract}

Keywords: knowledge; diarrhea; sanitation clinic

\section{PENDAHULUAN}

Puskesmas

peranan penting dalam meningkatkan derajat kesehatan masyarakat. Sebagai ujung tombak paling depan dalam pelayanan kesehatan puskesmas seyogyanya menerapkan upaya promotif, preventif dan kuratif secara terintegrasi ${ }^{1}$. Jika puskesmas hanya menonjolkan aspek kuratif maka tidak akan maksimal dalam mengatasi kasus Penyakit Berbasis Lingkungan $(\mathrm{PBL})^{2}$.
Salah satu terobosan untuk mengatasi masalah kesehatan berbasis lingkungan adalah klinik sanitasi. Berdasarkan Laporan Tahunan Kasus Diare di Wilayah Kerja Puskesmas III Denpasar Selatan (2017), jumlah kunjungan pasien diare ke poli umum sebanyak 938 jiwa, sedangkan jumlah rujukan konseling pasien PBL ke klinik sanitasi hanya 66 orang. Hal tersebut menunjukkan tingkat keberhasilan program klinik sanitasi Puskesmas 
III Denpasar Selatan masih rendah yaitu $7,04 \%^{3}$.

Tujuan penelitian untuk mengetahui hubungan tingkat pengetahuan dengan kunjungan pasien diare di klinik sanitasi Puskesmas III Denpasar Selatan. Manfaat penelitian sebagai bahan dalam menentukan kebijakan terkait penerapan upaya promotif dan preventif secara menyeluruh,

\section{METODE PENELITIAN}

Jenis penelitian termasuk penelitian observasional analitik dengan model pendekatan cross sectional yaitu menganalisa antara variabel bebas berupa tingkat pengetahuan pasien diare dengan variabel terikat yaitu kunjungan klinik sanitasi ${ }^{4}$. Populasi dan besar sampel penelitian adalah pasien diare di Puskesmas III Denpasar Selatan pada April 2019 sebanyak 54 responden, dimana semua anggota populasi digunakan sebagai sampel (Nonprobability Sampling atau Sampling Jenuh) sehingga penelitian bersifat generalisasi dengan kesalahan yang sangat kecil ${ }^{5}$. Teknik pengumpulan data dengan menggunakan angket berupa kuesioner yang sudah diuji dahulu validitasnya serta wawancara dengan pihak terkait. Pada penelitian ini menggunakan uji analitik chi square dengan kemaknaan $p<0,05$. Interpretasi hasil dilakukan jika nilai korelasi $p=0,000$ yang diartikan ada hubungan antara variabel bebas dengan variabel terikat, serta dilakukan perhitungan $C C$ untuk mengetahui keeratan hubungan antara kedua variabel tersebut ${ }^{6}$.

\section{HASIL DAN PEMBAHASAN}

\section{A. Tingkat Pengetahuan Pasien Diare}

Hasil pengamatan terhadap 54 pasien subyek penelitian dapat dilihat bahwa tingkat pengetahuan pasien diare tentang klinik sanitasi dikategorikan kurang yaitu 28 pasien $(51,9 \%)$, pengetahuan baik sebanyak 26 pasien $(48,1 \%)$.

Dilihat dari tingkat pengetahuan pasien diare tentang klinik sanitasi dominan memiliki pengetahuan yang dikategorikan kurang. Masyarakat seharusnya paham terkait klinik sanitasi sebagai salah satu pelayanan kesehatan di puskesmas dalam bentuk konsultasi dan penyuluhan penyakit bersumber 
dari lingkungan. Penelitian Widya dkk, 2014 dalam Husnawati, dkk, 2017 didapatkan hasil bahwa dari 90 responden, 84 orang yang tidak mengetahui pengertian dari klinik sanitasi dan hanya 6 orang yang mengetahui pengertian dari klinik sanitasi. Selain itu, terdapat 50 orang dari 90 responden $(55,5 \%)$ tidak mengetahui jika di puskesmas ada pelayanan klnik sanitasi dan 40 orang sisanya sudah tahu ${ }^{7}$.

\section{B. Kunjungan Klinik Sanitasi}

Hasil pengamatan terhadap 54 pasien dapat diketahui bahwa kunjungan pasien diare ke klinik sanitasi dominan memilih tidak berkunjung yaitu 44 pasien $(81,5 \%)$, sedangkan yang memilih berkunjung hanya 10 pasien $(18,5 \%)$.

Penelitian Widya dkk, 2014 dalam Husnawati, dkk, 2017 bahwa ada 78 orang dari 90 responden $(86,7)$ yang tidak ingin berkunjung ke klinik sanitasi. Pada penelitian ini, sebanyak $24,1 \%$ responden tidak mengetahui mengenai tujuan dari klinik sanitasi, sehingga untuk proses selanjutnya mengalami hambatan yaitu responden tidak tertarik untuk berkunjung ke klinik sanitasi dikarenakan mereka tidak mengetahui apa itu klinik sanitasi dan tujuannya. Responden juga tidak dapat mempertimbangkan dengan baik untuk berkunjung atau tidak ke klinik sanitasi yang disediakan oleh puskesmas, selanjutnya responden juga tidak mencoba untuk memanfaatkan fungsi dari klinik sanitasi tersebut ${ }^{8}$.

\section{Hubungan Tingkat Pengetahuan Pasien Diare dengan Kunjungan Klinik Sanitasi}

Analisis bivariat menggambarkan ada atau tidaknya hubungan tingkat pengetahuan dengan kunjungan pasien diare ke klinik sanitasi di Puskesmas III Denpasar Selatan. Penggabungan sel menunjukkan bahwa pasien diare yang memiliki pengetahuan kurang sebanyak $51,9 \%$ yang seluruhnya tidak ingin berkunjung ke klinik sanitasi. Sedangkan, pasien diare yang berpengetahuan baik sebanyak $48,1 \%$, terdiri dari $18,5 \%$ ingin berkunjung ke klinik sanitasi dan $29,6 \%$ tidak ingin berkunjung ke klinik sanitasi. Hasil analisis statistik dengan menggunakan uji chi square menunjukkan nilai korelasi $p=0,000$ dan $C C=0,44$ dengan kemaknaan $p$ 
$<0,05$. Dengan demikian, dinyatakan bahwa terdapat hubungan yang bermakna dengan keeratan hubungan yang sedang antara tingkat pengetahuan dengan kunjungan pasien diare ke klinik sanitasi di Puskesmas III Denpasar Selatan.

Upaya yang dapat dilakukan untuk menjalankan klinik sanitasi adalah diperlukan kebijakan dari kepala puskesmas untuk membuat tim pelaksana dalam kegiatan klinik sanitasi dan merancang sebuah POA (Plan of Action) terkait upaya peningkatan rujukan klinik sanitasi di puskesmas, sehingga tujuan dari program dapat tercapai ${ }^{9}$. Berdasarkan hasil penelitian maka puskesmas perlu untuk membuat skema alur masuk pasien/klien ke klinik sanitasi dan menempatkannya di ruang tunggu pasien, adanya evaluasi secara rutin terhadap program klinik sanitasi oleh dinas kesehatan dalam bentuk pembinaan dan supervisi terhadap petugas puskesmas agar program klinik sanitasi dapat berjalan dengan maksimal. Selain itu, agar pasien klinik sanitasi tidak drop out sebaiknya ruangan klinik sanitasi bersebelahan dengan ruangan pemeriksaan pasien serta ruangan pelayanan klinik sanitasi diusahakan dalam keadaan kondusif. Pihak puskesmas dapat meningkatkan sosialisasi kunjungan mengenai klinik sanitasi kepada masyarakat, sehingga masyarakat dapat memanfaatkannya sesuai yang diharapkan dan bersikap lebih positif $^{10}$.

\section{SIMPULAN}

Berdasarkan hasil analisis menunjukkan bahwa tingkat pengetahuan pasien diare tentang klinik sanitasi dominan kategori kurang yaitu 28 pasien (51,9\%), hanya $24,1 \%$ yang mengetahui tujuan dari klinik sanitasi. Selain itu, pasien diare dominan memilih tidak berkunjung ke klinik sanitasi yaitu 44 pasien $(81,5 \%)$. Hasil uji statistik menunjukkan bahwa ada hubungan bermakna antara tingkat pengetahuan dengan kunjungan pasien diare ke klinik sanitasi di Puskesmas III Denpasar Selatan.

\section{SARAN}

Upaya yang dapat dilakukan sebagai bahan dalam menentukan kebijakan terkait peningkatan 
keberhasilan program klinik sanitasi adalah kepada instansi terkait untuk membuat tim pelaksana dan merancang POA (Plan of Action). Selain itu, menggerakkan dan memberdayakan sumber daya yang dimiliki oleh masyarakat itu sendiri, seperti tokoh - tokoh masyarakat, kader, keluarga dan organisasi kemasyarakatan. Pelayanan kesehatan lingkungan di puskesmas juga menjadi bagian penting dari standar pelayanan minimal kabupaten/kota yang merupakan indikator bagi pemerintah daerah $\mathrm{da}^{2}$ lam memberikan pelayanan terhadap masyarakatnya.

\section{DAFTAR PUSTAKA}

1. Muninjaya, A. Manajemen Kesehatan. (Penerbit Buku Kedokteran EGC, 2004).

2. Jamarin. Gambaran Pelaksanaan Program Klinik Sanitasi Puskesmas Kota Bukittingi. (2014).

3. UPTD-Puskesmas-IIIDenpasar-selatan. Laporan Tahunan Kasus Diare. (2017).

4. Notoatmodjo, S. Metode Penelitian Kesehatan. (2010). 5. Sugiyono. Metode Penelitian
Kuantitatif. (Alfabeta, 2013).

6. Sugiyono. Metode Penelitian Kuantitatif, Kualitatif dan

$R \& D$. (CV Alfabeta, 2012).

7. Husnawati. Hubungan

Pengetahuan Dengan

Pemanfaatan Klinik Sanitasi

Pada Ibu Bayi Dan Balita

Penderita Diare Akut.

(Lambung Mangkurat, 2017).

8. Triwibowo. Kesehatan Lingkungan dan K3. (Nuha Medika, 2013).

9. Ratnaningtyas. Evaluasi Program Klinik Sanitasi. (Airlangga, 2017).

10. Notoatmodjo, S. Prinsip

Dasar Ilmu Kesehatan Masyarakat. (Rineka Cipta, 2007). 